\title{
INTERPERSONAL RELATIONS IN NURSING
}




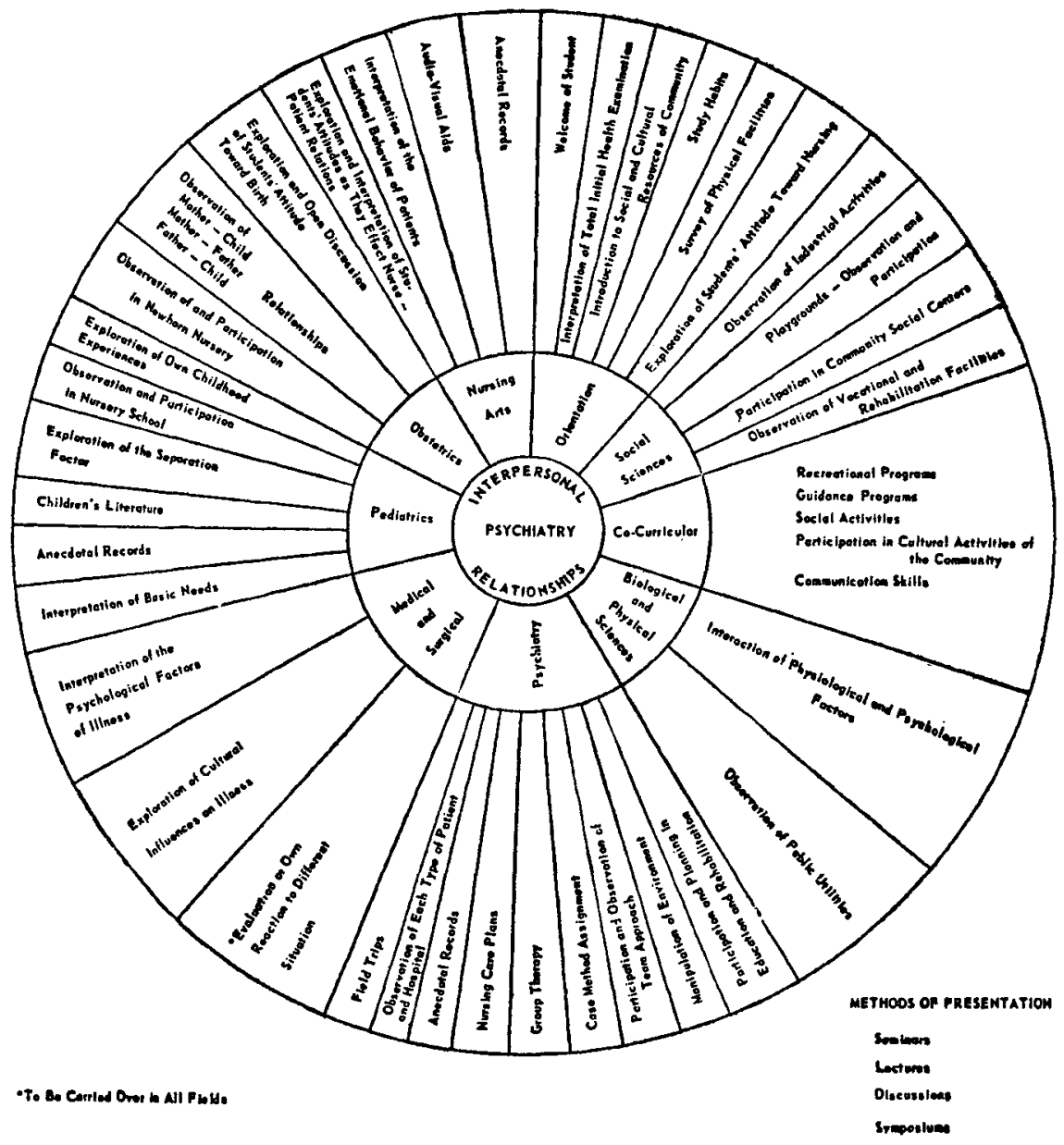

INTERPERSONAL RELATIONS IN THE BASIC CURRICULUM 


\section{Interpersonal \\ Relations in Nursing}

A Conceptual Frame of Reference for

Psychodynamic Nursing

Hildegard E. Peplau, RN, BA, MA, EdD

Professor Emerita

Rutgers, The State University of New Jersey, USA

Foreword by Trevor Clay, MPhil, RGN, RMN, FRCN

General Secretary

The Royal College of Nursing of the United Kingdom 


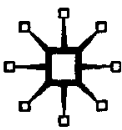

C 1952 edition G. P. Putnam's Sons

- 1988 edition Hildegard E. Peplau

All rights reserved. No reproduction, copy or transmission of this publication may be made without written permission.

No paragraph of this publication may be reproduced, copied or transmitted save with written permission or in accordance with the provisions of the Copyright, Designs and Patents Act 1988, or under the terms of any licence permitting limited copying issued by the Copyright Licensing Agency, 90 Tottenham Court Road, London W1T 4LP.

Any person who does any unauthorised act in relation to this publication may be liable to criminal prosecution and civil claims for damages.

The authors have asserted their rights to be identified as the authors of this work in accordance with the Copyright, Designs and Patents Act 1988.

Published by

PALGRAVE MACMILLAN

Houndmills, Basingstoke, Hampshire RG21 6XS and

175 Fifth Avenue, New York, N.Y. 10010

Companies and representatives throughout the world

PALGRAVE MACMILLAN is the global academic imprint of the Palgrave Macmillan division of St. Martin's Press, LLC and of Palgrave Macmillan Ltd. Macmillan is a registered trademark in the United States, United Kingdom and other countries. Palgrave is a registered trademark in the European Union and other countries.

ISBN 978-0-333-46112-9 ISBN 978-1-349-10109-2 (eBook)

DOI 10.1007/978-1-349-10109-2

This book is printed on paper suitable for recycling and made from fully managed and sustained forest sources.

A catalogue record for this book is available from the British Library.

Transferred to digital printing 2002 


\section{Preface}

AlL books reflect, in some degree, prevailing or emerging trends coincident with the era in which they were written. This book, originally published in $195^{2}$, is no exception to that point. It considered concerns of the nursing profession in the 1950 os and presented content intended to contribute toward their resolution. For instance, the question then being debated was "What is nursing?", which led to a definition of nursing as an interpersonal, investigative, nurturing, and growth-provoking process. Nursing was then viewed primarily as an art; this book presented some scientific aspects of nursing, such as theory with applications in nursing practice. A prevailing interest then was to define nursing activities in response to the question "What do nurses do?" This book shifted the question to "What do nurses know?", and focused on clinical nursing problems, concepts to explain observations, and principles to guide nurses in their work.

In writing this book, I believed that theories of interpersonal relations, then a new perspective on human interaction, were especially relevant to the work of nurses. This theoretical framework suggests that interaction phenomena that occur during nurse-patient relationships have qualitative impact on outcomes for patients. The principles and concepts introduced in this book are easily and beneficially applied in nursing practice. The concepts are basic ones-such as needs and anxiety-that provide a foundation for understanding more complex, related knowledge. In knowing and applying theory in order to understand the problems which patients present 


\section{vi PREFACE}

and to guide nursing interventions, nurses are adding a scientific component to the age-old arts of nursing.

In the past four decades, interpersonal theory has been greatly expanded by nursing research and by developments in the social sciences. Enrichment has also derived from such sources as theories of cognitive development and general systems theory. In other publications, I also have enlarged on the ideas presented in this original work. Nurse scholars, researchers, and clinical specialists in nursing, who found the I $95^{2}$ book a starting point, have pursued empirical studies and otherwise expanded the interpersonal perspective in nursing practice. But this book remains a useful foundation in interpersonal relations theory for nurses.

Professor Emerita, Rutgers University, September 1987

H.E.P. 


\section{Foreword}

THE other day I was talking with some students and members of the faculty in the Royal College of Nursing's Institute of Advanced Nursing Education in London. One said that she prized an illicit photocopy (from our Library in the RCN) of Peplau's Interpersonal Relations in Nursing. When I gave them the news that the book was to be republished I found myself wishing that Hildegard could have heard their whoops of joy.

This book will be received with delight by all nurses in the UK and, I believe, in so many countries of the world, as it is such an important event in the world of nursing literature.

The real reason why I believe nurses will welcome this book is that nursing in many parts of the world has lost its way with regard to the fundamentality of the nurse-patient relationship. Peplau's text and philosophy (yes-I use the word quite deliberately because I think she is truly a nursing philosopher) is clear and helpful and speaks a language which nurses want and need. We have concentrated in the last decade or so on the service of nursing - vitally important and necessary to continue so doing - but Peplau's mission is to concern herself with the art of nursing in order that it might complement and enable the service.

This book has well and truly stood the test of time, and from being described in the original Foreword as "one of the many beginning steps in studying and understanding interpersonal relations in nursing", it is now a vitally important leading work in this whole area. It is as fresh and necessary (no, more so) as 


\section{viii FOREWORD}

the day it was written. But what changes there have been in the climate of care service since it was written. Then, patients with elective surgical conditions stayed in hospital for Io-14 daysnow they stay for 10-1 4 hours. Then, the hospital was all-now it is only a part of the system, with people demanding more and more to be cared for in their own homes. Then, the emphasis was almost entirely on sickness, but now it is on health. These changes make the book all the more necessary and welcome. It will be used by nurses caring for the sick but it will be an exciting new discovery for nurses engaged in primary health care.

It is a privilege to have been asked by Hildegard Peplau to associate myself with this book and I do so wholeheartedly.

September ${ }_{1987}$ Trevor Clay, MPhil, RGN, RMN, FRCN General Secretary The Royal College of Nursing of the United Kingdom 


\section{Introduction}

There Is nothing new about the kind of nursing advocated in this work. Good nurses everywhere have in varying degrees been practicing it. The purpose of this text is to aid graduate nurses and nursing students to improve their relations with patients. Many nurse practitioners wish to deepen their understanding of interpersonal relations in nursing situations in order that their work will be more effective and socially useful. Clinical instructors seek new ways for helping nursing students to develop and improve their skill in interpersonal relations. Students look for books that summarize principles that are portrayed or symbolized in the behavior of nurses who are useful to patients. This work identifies for nursing some of the concepts and principles that underlie interpersonal relations and transform nursing situations into learning experiences. It provides a reference source of hypotheses that may be examined with profit in all nursing situations. It proposes concepts that may be learned and become incorporated into the functioning personality of every nurse who is willing to struggle toward greater maturity in her relations with others.

The expression "psychodynamic nursing" is of recent origin. Spelling out the accompanying psychiatric nursing skills -their use, meaning, and consequences in general nursing represents a more recent trend. Recognizing, clarifying, and building an understanding of what happens when a nurse relates herself helpfully to a patient are the important steps in psychodynamic nursing; nursing is helpful when both the 
patient and the nurse grow as a result of the learning that occurs in the nursing situation. These steps develop from the guiding assumption: the kind of person each nurse becomes makes a substantial difference to what each patient will learn as he is nursed throughout his experience with illness. Concepts, principles, skills, and abilities can be said to be learned when new behavior follows examination and discussion of problems that require particular principles and skills for their solution. Thus, a second guiding assumption can be stated: fostering personality development in the direction of maturity is a function of nursing and nursing education; it requires the use of principles and methods that permit and guide the process of grappling with everyday interpersonal problems or difficulties.

These two assumptions underlie this present work. The central task of the basic professional school of nursing is viewed as the fullest development of the nurse as a person who is aware of how she functions in a situation. A problemattacking or problem-solving method is viewed as one of the more important ways through which this task can be met. It allows the liberation and reinforcement of ongoing processes in individual nurses and in groups. It requires attention to the unfinished tasks of earlier personality development in each student, as well as learning of skills and methods that are likely to ensure continuing forward movement. What each nurse becomes-as a functioning personality-determines the manner in which she will perform in each interpersonal contact in every nursing situation. The extent to which each nurse understands her own functioning will determine the extent to which she can come to understand the situation confronting the patient and the way he sees it. Positive, useful nursing actions flow out of understanding of the situation. Release of human interest in others who are in difficulty, liberation of emotional and intellectual capacity for making choices, development of nurses as persons whose enlightened self-interest will lead to no other choice but productive relations with all kinds of patients, students, citizens 
- these are tasks related to the central one stated above. The basic task of the school of nursing ought not to be "concern for the patient", which is the task of nursing service; the task of the school of nursing is the gradual development of each nurse as a person who wants to nurse patients in a helpful way. Attention to this task is a guarantee of useful improvement in nursing practice.

This book is written with a view to aiding nurses and professional school personnel to recognize the importance of the nurse's personality in interpersonal relations in nursing situations. It identifies concepts and principles relevant to the promotion of psychodynamic nursing and to the resolution of interpersonal difficulties in clinical and other situations. It assumes that every nurse-patient relationship is an interpersonal situation in which recurring difficulties of everyday living arise. It recognizes that every nurse-nurse relationship is an opportunity for tackling collaboratively those disagreements in point of view that are inevitable. It takes for granted that every instructor-student relationship is an experience in interpersonal relations that becomes problematic at one time or another. Every administrator-staff nurse relationship is an interpersonal situation that calls out older feelings, unsolved difficulties, and often re-enacts problems generated in prior relationships. In every contact with another human being there is the possibility for the nurse of working toward common understandings and goals; every contact between two human beings involves the possibility of clash of feelings, beliefs, ways of acting. In nursing situations professional personnel have the obligation and the necessity to use their greater skill. Being able to understand one's own behavior, to help others to identify felt difficulties, and to apply principles of human relations to the problems that arise at all levels of experience - these are functions of psychodynamic nursing. Helping nurses to understand the relationship of nurse personalities to these functions is an aim of this work.

The day is long past when any one clinical instructor can be expected to know all of the problems and all of the prin- 
ciples connected with one field of work. Every instructor elects and continues to expand that which has come to her attention as relevant to nursing. Likewise, this work represents a selection of hypotheses and ideas from many sourcesa selection that seemed to the author to represent basic concepts consistent with the behavior of nurses who are relatively skilful in interpersonal relations. Since it is not intended that any nurse shall limit herself to the scope of this book, references are suggested that will permit further exploration. The social sciences and psychiatry will continue to expound new ideas of importance in the solution of common nursing problems that recur in varied nursing situations.

Difficulties in human relations are not usually solved once and for all. Nor can all of the problems that we now face be fully understood in terms of ideas currently available. Nursing, as an applied science, is in a unique position to identify and study the scope, range, and varying intensities of recurring human problems that have to be faced in everyday living. Moreover, nurses help patients to meet problems at times when they are undergoing additional stresses and strains. Nurses are also in a position to identify and study degrees of skill that people use in struggling with presenting difficulties and to develop with patients the kinds of new experiences that are needed for such skill improvement. Assistance in the identification of problematic situations, appreciation and liberation of positive forces in patient personalities are functions of the nurse. As each nurse helps a patient to identify problematic elements in his current situation and to discover and understand something about what is happening to him during his illness, she both expands her own insights and helps the patient to grow. Thus, the nurse in some degree enables the patient to appreciate the same principles that she makes use of as she exemplifies a helping person to one in need.

Difficulties in interpersonal relations recur in varying intensities throughout the life of everyone. Sometimes the degree of skill is greater at a later date; sometimes individuals 
meet adult versions of an infant problem with infantile skills. The problems related to dependence provide an example: being dependent upon others is a problem that begins in infancy, changes its intensity and mode of expression as one proceeds from infancy, through adolescence, adulthood, and old age; the need can become problematic at any point in life and is the same need as seen in the infant. Only the skill with which the difficulty is evaluated and met changes as personality develops, is modified, and functions in changing situations. Each nurse should be able to identify human problems that confront patients, the degrees of skill used to meet situations, and be able to develop with patients the kind of relationships that will be conducive to improvement in skill.

Recurring difficulties can be met with greater skill at some future date, by each patient and each nurse, only when current interpersonal relations are characterized by useful learning. School of Nursing personnel provide the training ground for student nurses. The method by which each clinical instructor aids her trainees, basic students, to define problems and to discover and use principles in order to understand and resolve difficulties is the method that will most likely be learned. If it is exemplary of the one to be used in the nursepatient relationship, the method will be transferred from the nursing laboratory to the clinical situation. If one method is used in the classroom and an entirely different kind is advocated for interpersonal relations in the sickroom, the student nurse is likely to be confused about the methods involved in a concept of "nurse."

Each clinical instructor, as well as every graduate nurse who has contact with students, stands for and exemplifies the meaning of the nurse concept. Whatever interpersonal relations are developed with students will, to a considerable extent, influence the concept of nursing that these students will learn. When the instructor or supervisor stands for a person who grapples with problems, inquires into new resources in order to understand the difficulty, and functions democratically with others, these qualities will tend to be evoked in 


\section{Xiv INTRODUCTION}

students. To a marked degree students will relate to patients in the manner in which significant others (other individuals significant to them in their early life) have related to them. The patterning of student behavior may be relatively simple, clinical instructors merely reinforcing patterns already learned in parental contacts and in relations with teachers met in the past. Where the clinical instructor represents a clearly new pattern-and mature democratic behavior is all too frequently a new pattern to be learned-the student's wish to become like the instructor may generate difficulties, and reinforcement of earlier patterns may be impossible. When the clinical instructor's pattern of relations with students is largely a productive one she will be able to aid those students in continuing the forward struggle, in managing their frustrations, conflicts, and anxieties as older patterns of behavior are foregone and more productive, new ones are developed. As students experience this kind of useful assistance, in an interpersonal situation that is characterized by expansion of personality and productive learning, enough is learned about the method so that initially interest can develop. Deepening student understanding of the processes through which help is offered to others begins with the instructor-student relationship.

Whatever is experienced by basic students in their relations with graduate nurses in a professional program helps to pattern the behavior that will operate when they, in turn, become practicing graduate nurses. In order to understand the limitations of current practitioners it is necessary to look at the learning experiences that helped lay down patterns of present behavior. In order to recognize the kinds of patterns that are considered desirable for graduate nurse practitioners it is necessary to look at nursing situations and to find out what are the tasks or performances that are demanded of nurses; that is, not the activities of nurses now practicing but the tasks that emerge in a nurse-patient relationship. What kinds of tasks do patients present to nurses? What are the psychological demands that patients make in the presence of 
professional persons? How shall these demands be met so that personality of patient and nurse can be strengthened? What are the principles that govern the ways in which nurses might respond to these psychological tasks? These are questions that provide a basis for identifying the functions of psychodynamic nursing. Understanding what is involved in nurse-patient relationships is the only basis on which learning experiences for student nurses, who will develop skill in being helpful in interpersonal situations, can be designed.

While the basic school can do much to foster the development of students as useful, productive persons, each graduate nurse can also take on the responsibility for expanding her own insight into the effects of life experiences on personality functioning and for planning steps that will lead to a mode of life that is more creative and more productive. If this text proves to be helpful in an exploration of the conceptual framework and the identification of method that assists in this self-enlightenment, it will have served the useful purpose for which it has been written. 


\section{Contents}

Preface v v

Foreword vii

Introduction $\quad$ ix

Illustrations $\quad$ xix

Part I. Phases and Roles in Nursing Situations

I. A Definition of Nursing 3

2. Phases of Nurse-Patient Relationships I7

3. Roles in Nursing 43

Part II. Influences in Nursing Situations

4. Human Needs 73

5. Interferences to Achievement of Goals 85

6. Opposing Goals 99

7. Unexplained Discomfort $\quad$ I 9 


\section{xviii CONTENTS}

\section{Part III. Psychological Tasks}

8. Learning to Count on Others I6 I

9. Learning to Delay Satisfaction $\quad$ I 89

Io. Identifying Oneself 209

I 1. Developing Skills in Participation 239

\section{Part IV. Methods for Studying Nursing as an} Interpersonal Process

12. Observation, Communication, and Recording 263

Selected Bibliography (by topics) 


\section{Illustrations}

Fig. I. Aspects of word symbols.

Fig. 2. A continuum showing changing aspects of nursepatient relations.

Fig. 3. Overlapping phases in nurse-patient relationships. 21

Fig. 4. Role of leadership functions in two phases in a nurse-patient relationship, involving fluid intake.

Fig. 5. Phases and changing roles in nurse-patient relationships.

Fig. 6. Psychological experiences that provide energy that is transformed into various forms of behavior.

81

Fig. 7. Actions involved in frustration.

Fig. 8. "Polar constructs" and varying degrees of anxiety, conceptualized on a continuum, according to Sullivan.

Fig. 9. Mothering experiences that have positive weight in total personality formation and functioning.

Fig. Io. Mothering experiences that have negative weight in total personality formation and functioning. 


\section{xx ILLUSTRATIONS}

Fig. It. A fiftcen-year-old boy's drawings that show a series of experiences in which he felt "cut off" in various ways.

Fig. 12. A four-year-old child draws a picture in which she achieves unity of her father, mother, and herself, in a way in which it cannot be achieved in her present situation.

Fig. 13. A sampling of responses of twenty-one students to a simple pretest on the meaning of behavior to the patient, as recognized by the observer.

Fig. 14. Sequential arrangement of maturation of skills required for competent professional nursing.

Fig. 15. Pictorial presentation of kinds of observers, according to Lasswell.

Fig. I6. A relationship of meaning to events and to physiological functioning.

296

Fig. 17. A form for recording relations in nursing. 